\title{
O poema em prosa em foco
}

$\mathbb{R}$ ECENTEMENTE lançado pela Iluminuras, Arte da pequena reflexão: poema em prosa contemporâneo, de Fernando Paixão, como assinala o próprio autor, debruça-se sobre um tema que, apesar de sua grande importância para o desenvolvimento da poesia no século XX, ainda não foi devidamente estudado - o poema em prosa. Fernando Paixão avança e explora algumas das possibilidades dessa forma poética na produção contemporânea.

Fruto de sua tese de doutorado, defendida na PUC de São Paulo em 2004, o livro se coloca três grandes questões: Como definir o poema em prosa? Que tipo de linguagem esse gênero prioriza? Quais são suas características?

Perguntas tão abrangentes e fundamentais exigem, como bem nota o autor, necessariamente um recorte. Em seu trabalho, optou por partir das origens francesas, colocando algumas questões iniciais justamente a partir daquele que elaborou primeiro as bases do gênero, isto é, Charles Baudelaire e seus Petits poèmes en prose, publicados em 1869. A cuidadosa pesquisa empreendida, inspirada em trabalhos como o de Suzanne Bernard, leva a discussão a textos bem anteriores ao de Baudelaire; iniciando com Les aventures de télémauque, de Fenelon, publicado em 1699, passando por autores como Marmotel, Parny, Flocon e Mérimé, para chegar assim ao precursor de Baudelaire, Aloysius Bertrand. Mas, como indica um dos capítulos do livro, o "gênio do gênero" é mesmo Baudelaire e é a partir dele que a reflexão é conduzida. A citação de Baude- laire, em tradução de Aurélio Buarque de Holanda escolhida por Paixão, é uma das que melhor sintetizam a nova poética em curso à época:

qual de nós, em seus dias de ambição, não sonhou com o milagre de uma prosa [que fosse] poética, musical sem ritmo e sem rima, bastante maleável e bastante rica em contrastes para se adaptar aos movimentos líricos da alma, às ondulações do devaneio, aos sobressaltos da consciência?

Pode-se dizer que ela é um mote para o estudo. Na Parte I do livro, dedicada a tópicos de linguagem e de composição, o que interessa é, nas palavras do próprio autor, "capturar a dinâmica do poema em prosa”. Capturá-la implica, aqui, justamente debruçar-se sobre "movimentos líricos". Para tal, as noções escolhidas foram metonímia e fragmento, narração e descrição, além do ritmo, por vezes também chamado de melopeia. Fernando Paixão inicia sua análise discutindo, a partir de Agamben, a identificação do enjambement como aquilo que define a poesia em oposição à prosa. Interessa à discussão o fato de a quebra do verso "interferir no ritmo e até mesmo no imaginário dos versos" ou ainda o fato de a linearidade tipográfica do poema em prosa reforçar sua discursividade. Essa linha de argumentação, por se interessar pela "configuração de um imaginário distinto", retoma a tese de Barbara Johnson de que o poema em prosa se caracterizaria pela predominância da metonímia como figura de linguagem, diferentemente do poema 
em versos, mais inclinado ao uso de metáforas. Fernando Paixão coloca à prova esse princípio por meio da análise de um poema de Charles Simic, no qual verifica a presença de um "efeito de contiguidade"; constatação que não o impede de atentar para o risco de generalização da premissa. Abre-se assim o campo para a discussão da "fragmentação" como outro possível mecanismo característico do poema em prosa; a análise, dessa vez, é ilustrada por um poema do espanhol Andrés Sánches Robayna.

Esse procedimento de close reading é replicado ao longo do livro, permitindo ao leitor acessar in loco os mecanismos; dentre os quais Paixão destaca outro par - narração e descrição. Para o autor, no poema em prosa, como demonstra ao longo de dois instigantes capítulos, a narrativa encontra-se "sob tensão" e a descrição cria uma "semiose intensiva”. Um terceiro e último princípio que "participa diretamente da composição do poema em prosa" é o ritmo. Com sua capacidade de traçar de modo claro e objetivo panoramas históricos, Paixão explica que, mesmo se diferente das noções de ritmo simbolistas e de futuristas, esse continua a cumprir um papel importante na construção do poema em prosa.

Está em jogo a criação de repetições, de ecos e de pausas que sustentam e "emprestam vivacidade às imagens", mas o modo como o ritmo se configura é bem diferente. Ao analisar um poema de Ferreira Gullar, o autor destaca que o que caracterizaria seu ritmo seria a estrutura e a imagem da primeira frase, assim como o encadeamento da enumeração que segue. Nessa dinâmica, a pontuação, a tonalidade das frases, os torneios vocálicos vão constituindo o poema, no qual

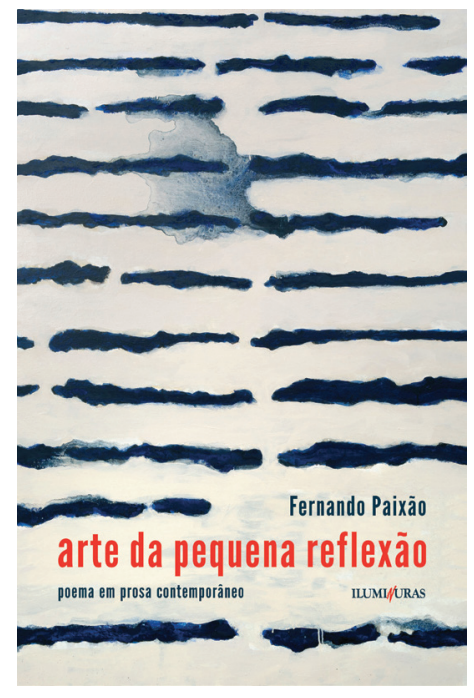

PAIXÃO, F. Arte da pequena reflexão: poema em prosa contemporâneo.

São Paulo: Iluminuras, 2014. 212p.

"as imagens, e não somente as palavras, interagem com os efeitos do ritmo". Como se pode notar nas duas citações aqui, elementos linguísticos são relacionados à imagem e ao imaginário. Com efeito, esses parecem ser centrais em sua reflexão e parecem ser o "algo mais" citado no capítulo sobre o ritmo - intitulado "melopeia e algo mais".

Se retomarmos os princípios que caracterizam o poema em prosa ao longo do livro é possível notar, por exemplo, que o autor, ao descrever o efeito do enjambement, destaca que "esse recurso de linguagem [...] produz um efeito correspondente no imaginário"; ao referir-se à metonímia, aponta que essa ideia-síntese "permite captar certos mecanismos imaginários ligados ao gênero"; ao reescrever em versos um poema em prosa de Simic, explica que "é possível perceber certa mudança de tonalidade e de colorido no poema, quando as imagens parecem transfiguradas em 


\section{Charles Baudelaire (1821-1867)}

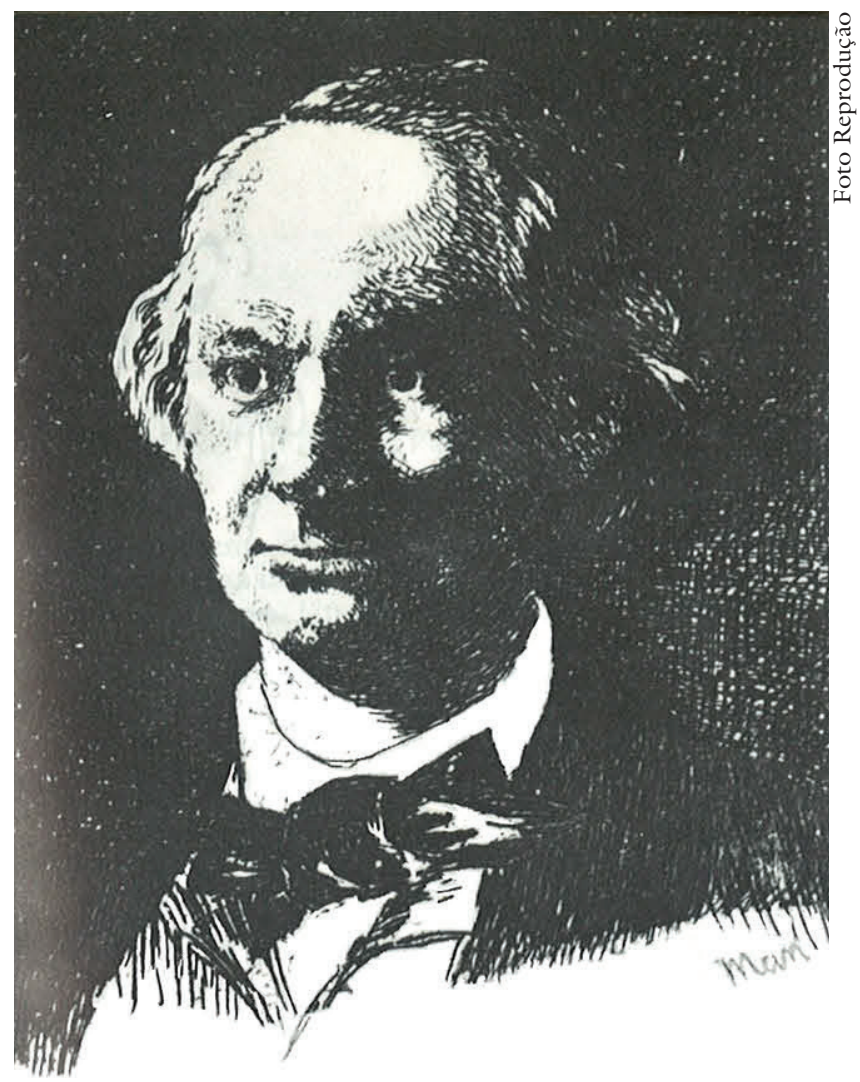

versos". Os exemplos se multiplicam ao longo das análises e colocam em evidência a importância do ritmo, muitas vezes chamado de "fluência", "cadência", "respiração", fazendo que seja o produtor de um "tônus narrativo", um "fluxo narrativo", uma "linha de ação" característico do poema em prosa. É o próprio autor quem afirma na página 129 :

[...] a natureza rítmica desse tipo de escrita funciona ao modo de uma linha contínua. Cabe ao poeta puxá-la e compor um traçado próprio, sugerir imagens utilizando o contraponto de palavras, tons, espaços e pontuações. O fluxo das frases corresponde ao movimento da linha.

Para ilustrar a diversidade de traçados, é mobilizada uma considerável variedade de autores, de diversas nacionalidades, $\mathrm{O}$ que leva à construção de uma rica co- letânea de poemas em prosa, formada por nomes como os de René Char, Pierre Louÿs, Czelaw Milosz, James Tate, Mário Quintana, Jorge de Lima, Murilo Mendes, Francis Ponge, Alejandra Pizarnik, Ferreira Gullar, Carlos Drummond de Andrade, Edmond Jabès, Zulmira Ribeiro Tavares, Yves Bonnefoy... Sendo Charles Simic e Herberto Helder merecedores de capítulos a parte.

Enfim, o amplo leque de línguas em que os poemas originais foram escritos somado ao entendimento do ritmo, sobretudo como produção de contrapontos de palavras, tons, espaços e pontuações, talvez justifique o fato de as análises serem feitas, na maioria das vezes, a partir das traduções sem que o original seja reproduzido; uma ausência sentida para os conhecedores das línguas originais, que poderiam, por meio do 
cotejamento, acessar algumas camadas que nem sempre as traduções abarcam. Essa ausência, contudo, não impede que esse trabalho venha preencher uma importante lacuna no Brasil, ainda mais se levarmos em conta o lugar central que essa "arte da pequena reflexão" ocupa no espaço lírico contemporâneo.

Álvaro Faleiros é doutor em Letras pela Universidade de São Paulo (2003); professor de Literatura Francesa da FFLCHUSP. @- faleiros@usp.br

${ }^{\text {I }}$ Faculdade de Filosofia, Letras e Ciências Humanas, Universidade de São Paulo, São Paulo/SP, Brasil. 